\title{
Examination of Stroke Mechanics and Athletic Performance Components in Swimmers According to Age Categories
}

\author{
Burcu Ertas Dolek ${ }^{1} \&$ Elif Cengizel ${ }^{2}$ \\ ${ }^{1}$ Ankara University, Faculty of Sport Science, Ankara, Turkey \\ ${ }^{2}$ Gazi University, Faculty of Sport Science, Ankara, Turkey \\ Correspondence: Burcu Ertas Dolek, Ankara University Gölbaşı Campus Faculty of Sport Sciences 06830, \\ Gölbaşı, Ankara, Turkey. E-mail: bdolek@ankara.edu.tr
}

Received: August 3, 2019

Accepted: August 27, 2019

Online Published: September 20, 2019

doi:10.5539/jel.v8n5p219

URL: https://doi.org/10.5539/jel.v8n5p219

\begin{abstract}
At the beginning of the components that affect the performance of the swimmers' training and race planning, the stroke count (SC), stoke lenght (SL) and stroke rates (SR) of the swimmers are important. For this reason, it is important for both athletes and coaches to know how to develop and change these characteristics with age. The aim of this study is to investigate the change in athletic performance and body structure of 9-15 age group. A total of 50 students were participated in the study. Subjects were divided into two groups as below 12 years of age $\left(<12\right.$ years, $\left.\mathrm{n}_{\text {male }}=14, \mathrm{n}_{\text {female }}=14\right)$ and 12 years of age and older $\left(\geq 12\right.$ years, $\left.\mathrm{n}_{\text {male }}=11, \mathrm{n}_{\text {female }}=11\right)$. The athletic performance variables are grouped in such a way as jump (vertical and horizontal) and swim data (50 m free swimming time, number of SR, SC, SL). Descriptive statistics were used for the groups and Mann Whitney $\mathrm{U}$ test was used for comparison between groups $(\mathrm{p}<0.05)$. A significant difference was found between all groups except SR, and in the jump performance (horizontal \& vertical) with age. There was no significant difference in stroke rate and stroke time in kinematic parameters; as a result of the significant difference found in the SC and SL, $50 \mathrm{~m}$ freestyle swimming times decreased with age. As a result; it is thought that following this changing process for each age group of coaches will contribute significantly to the swimming performances of the athletes.
\end{abstract}

Keywords: swimming, performance, stroke rate, stroke count, swimmer students

\section{Introduction}

Since 1896 when modern Olympics started to be organized, swimming has been one of the branches that host the highest number of competitions together with athletics. It hosts 42 competitions between $50 \mathrm{~m}$ and $1500 \mathrm{~m}$, both individually and as a team. This situation has led countries to make more investment in these branches in order to achieve more success in the Olympic Games and to focus on scientific studies more. In 1912, women took part in the Olympics for the first time, and in 1922, Johnny Weissmuller became the first athlete who finished the $1100 \mathrm{~m}$ freestyle under 1 minute. When the 42 competitions in the Olympic Games are examined, 22 of them consist of $50 \mathrm{~m}$ and $100 \mathrm{~m}$ races swum under 1 minute (Natation-FINA, 2015). When the durations and distances of the competitions are taken into consideration, the strategies used by the swimmers during their trainings and the performances they exhibit in the race gain importance (Aspenes, Kjendlie, Hoff, \& Helgerud, 2009; Barbosa, Fernandes, Keskinen, \& Vilas-Boas, 2008). Swimmers who are able to learn and apply these strategies at an early age will be able to critically observe their capacities and performances and have the ability to adapt them when necessary. The performance of the swimmers in the competitions is determined by physical, physiological and psychological characteristics and traditional swimming trainings are basically planned to improve the physiological capacity of the swimmer. In addition to traditional methods, the stroke counts (SC), stroke lengths (SL), stroke rates per minute (SR) of the athletes taken along the distance are among the components that affect performance in the training and race-related plannings of swimmers (Craig \& Pendergast, 1979). In the branch of swimming where the same motion cycle should be continuously performed at high quality, the most basic requirement for the achievement of success against time is to have well knowledge on the motion and training effects (Barbosa et al., 2019). Therefore, knowing how these characteristics will develop and change with age is important for both athletes and coaches for the efficiency of the training. Based on the principle of swimming faster by consuming less energy, training plans will be able to gain different dimensions. If swimmers create 
their SR according to the distances they will swim, they can establish race and training strategies, manage their race strategies more easily and perform their trainings more effectively (Veiga, Rodriguez, González-Frutos, \& Navandar, 2019). When swimmers are able to learn and apply these components and their effects at an early age, they will be able to interpret their performances more critically. They should practice the SR strategies that will be followed in the races in their trainings frequently. Although the literature on youth swimmers is scarce, youth swimmers demonstrate more variable pacing profiles (Menting, Elferink-Gemser, Huijgen, \& Hettinga, 2019).

The relationship between swimmers' trainings, competition performances and the energy they spend is of great importance for the success gained. The energy and time spent are important for performance efficiency. Since the number of studies conducted on performance components of swimmers is very limited, it is planned to bring a new perspective to this area. The relationship between stroke parameters and performance development in swimmers needs to be further explored in future studies. The aim of this study is to examine of stroke mechanics and athletic performance components in swimmers according to age categories.

\section{Method}

\subsection{Subjects}

Female \& male 50 students in total participated in the study conducted with an aim to examine the change of 915 age group swimmers' athletic performances and body structures according to age categories. The subjects were divided into two groups as the group below the age of 12 years $\left(<12\right.$ years of age, $\left.\mathrm{n}_{\text {female }}=14, \mathrm{n}_{\text {male }}=14\right)$ and the group above the age of 12 years $\left(\geq 12\right.$ years of age, $\left.\mathrm{n}_{\text {female }}=11, \mathrm{n}_{\text {male }}=11\right)$. Before starting the study, each participant and his/her parent completed the 'Informed Voluntary Consent Form'.

The criterion for participating in the study is to be training at least 3 times a week for the last 2 years in the 10 16 age group in swimming team. In case that the participants had any chronic disease or were using any drug and they had any injury or surgical operation 6 months before the measurement day, they were not included in the study (10 athletes). 24 hours before all the tests, the participants were informed about not using caffeine, drug and substances included in the scope of ergogenic aid and avoiding high intensity exercises.

\subsection{Study Protocol}

Anthropometric measurements of the athletes were determined by Holtain brand (UK) stadiometer, body compositions of the athletes (body analysis with right $\&$ left upper and lower extremities) were determined by bioimpedance device (Tanita BC 418 (Japan) body composition analyzer measuring with $0.1 \mathrm{~kg}$ sensitivity). By calculating the rate of the measured lengths and stroke lengths, APE Index value was found. Horizontal and vertical jump performance values, which were determinant for the starting and turning speeds of the swimmers, were measured. Vertical and horizontal jump tests are used to determine the lower body (leg) strength (Weimar et al., 2019). They were preferred because the two of them are used at starts and turns in swimming. Vertical and horizontal jump tests were performed with the help of mats arranged for these tests. Since swimming is a sports branch where our body is used multidimensionally, these data were needed because of including horizontal and vertical jumps at starts and turns.

$50 \mathrm{~m}$ freestyle swimming degrees were measured (F-1.30.040 Finis Stopwatch 3x300M was used) and then the SC, SL and SR of the athletes were calculated. All measurements were performed at the morning hours on the predetermined days. In all performance tests, the athletes were allowed to try 2 times and the best score was taken into account.

All the measurements were performed in Public Swimming Pool during the training hours of the swimming team. The study plan is given in the table below.

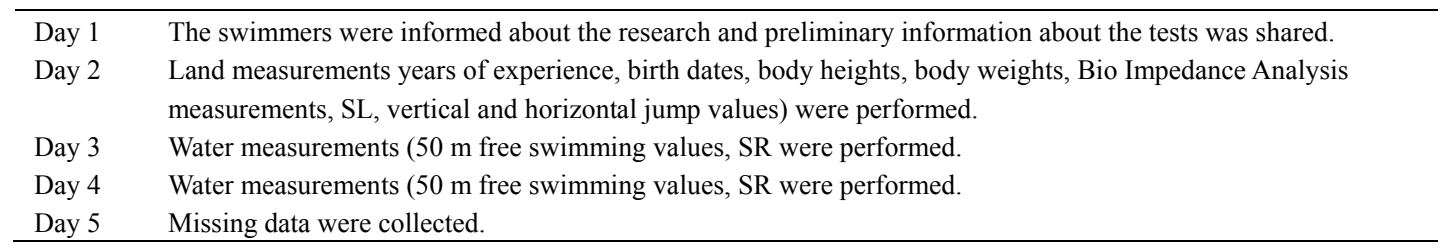

To define performance in swimming, the following parameter should be mentioned.

Stroke rate (SR): Stroke count per minute (stroke/minute)

Stroke count (SC): Stroke count in the distance (stroke count) 
Stroke Lenght (SL): Arm span lenght (cm)

Distance Per Stroke (DPS): Distance taken per stroke ( $\mathrm{m} /$ stroke count)

APE index: The ratio between the individual's arm span and height

\subsection{Statistical Analysis}

SPSS 22.0 package program (License Number:9888978) was used to evaluate the descriptive statistics. Descriptive statistics regarding the groups were conducted and the Mann-Whitney U test was used for the comparison between the groups.

\section{Results}

Table 1. Characteristics of the subjects

\begin{tabular}{llll}
\hline & $\begin{array}{l}<12 \text { years of age } \\
(\mathrm{n}=28)\end{array}$ & $\begin{array}{l}\geq 12 \text { years of age } \\
(\mathrm{n}=22)\end{array}$ & $\mathrm{p}$ \\
\hline Age (years) & $10.0 \pm 0.8$ & $13.4 \pm 1.1$ & $<0.001$ \\
Years of experience (years) & $3.5 \pm 1.0$ & $6.4 \pm 1.1$ & $<0.001$ \\
Body height $(\mathrm{cm})$ & $141.6 \pm 11.0$ & $158.1 \pm 9.3$ & $<0.001$ \\
Body weight $(\mathrm{kg})$ & $35.8 \pm 10.2$ & $47.4 \pm 9.6$ & $<0.001$ \\
\hline
\end{tabular}

It is seen that as the ages of the swimmer group increase, their sport ages also increase. The mean age of the group below 12 years of age was found as $10.0 \pm 0.8$ years, the mean length was found as $141.6 \pm 11.00 \mathrm{~cm}$ and the mean stroke length was found as $142.3 \pm 7.5 \mathrm{~cm}$ (Table 1). According to these results, APE index values were determined as $1.004 \pm 0.026$. The mean age of the group above 12 years of age was found as $13.4 \pm 1.1$ years, the mean length was found as $158.1 \pm 9.3 \mathrm{~cm}$ and the mean stroke length was found as $161.7 \pm 9.7 \mathrm{~cm}$. According to these results, APE index values were calculated as $1.023 \pm 0.024$ (Table 2).

Table 2. Swimming and performance data of the subjects

\begin{tabular}{llll}
\hline & $\begin{array}{l}<12 \text { years of age } \\
(\mathrm{n}=28)\end{array}$ & $\begin{array}{l}\geq 12 \text { years of age } \\
(\mathrm{n}=22)\end{array}$ & $\mathrm{p}$ \\
\hline $50 \mathrm{~m}$ freestyle $(\mathrm{sec})$ & $42.2 \pm 5.7$ & $35.6 \pm 3.7$ & $<0.001$ \\
SL $(\mathrm{cm})$ & $142.3 \pm 7.5$ & $161.7 \pm 9.7$ & $<0.001$ \\
APE Index & $1.004 \pm 0.026$ & $1.023 \pm 0.024$ & 0.01 \\
SR (stroke/minute) & $46.9 \pm 6.8$ & $49.1 \pm 6.3$ & $\mathbf{0 . 1 7 4}$ \\
SC (count) & $60.4 \pm 6.4$ & $52.1 \pm 8.0$ & $<0.001$ \\
DPS (m) & $0.84 \pm 0.1$ & $0.98 \pm 0.15$ & $<0.001$ \\
Vertical jump $(\mathrm{cm})$ & $25.2 \pm 12.0$ & $29.6 \pm 5.3$ & 0.001 \\
Horizontal jump $(\mathrm{cm})$ & $130.0 \pm 29.4$ & $142.3 \pm 25.2$ & 0.041 \\
\hline
\end{tabular}

Note. ${ }^{*}$ No significant difference.

In kinematic parameters, no significant difference was found between the mean SR values among the groups. Statistically significant differences were found between the means of $50 \mathrm{~m}$ freestyle swimming degrees, SL, APE index values, SC, DPS and jump performances (vertical and horizontal, Table 2). 
Table 3. Body composition data of the subjects

\begin{tabular}{|c|c|c|c|c|}
\hline & & $\begin{array}{l}<12 \text { years of age } \\
(\mathrm{n}=28)\end{array}$ & $\begin{array}{l}\geq 12 \text { years of age } \\
(\mathrm{n}=22)\end{array}$ & $\mathrm{p}$ \\
\hline \multirow[t]{5}{*}{ Total body } & BMI & $17.6 \pm 2.9$ & $18.9 \pm 2.2$ & $0.069^{*}$ \\
\hline & BMR & $1233.1 \pm 201.4$ & $1433.8 \pm 219.3$ & 0.001 \\
\hline & Fat percentage $(\%)$ & $21.3 \pm 4.2$ & $20.4 \pm 4.8$ & $0.363^{*}$ \\
\hline & Fat mass (kg) & $7.8 \pm 3.3$ & $9.7 \pm 3.3$ & 0.026 \\
\hline & LBM (kg) & $27.9 \pm 7.6$ & $37.5 \pm 8.0$ & $<0.001$ \\
\hline \multirow[t]{4}{*}{ Trunk } & Fat percentage (\%) & $14.9 \pm 4.3$ & $14.8 \pm 4.6$ & $0.961 *$ \\
\hline & Fat mass (kg) & $3.1 \pm 1.5$ & $3.8 \pm 1.6$ & $0.053^{*}$ \\
\hline & LBM $(\mathrm{kg})$ & $16.8 \pm 3.9$ & $21.7 \pm 3.8$ & $<0.001$ \\
\hline & PMM (kg) & $16.2 \pm 3.7$ & $20.8 \pm 3.7$ & $<0.001$ \\
\hline \multirow[t]{4}{*}{ Right leg } & Fat percentage (\%) & $28.4 \pm 4.6$ & $25.7 \pm 5.9$ & $0.075^{*}$ \\
\hline & Fat mass $(\mathrm{kg})$ & $1.8 \pm 0.8$ & $2.3 \pm 0.7$ & 0.022 \\
\hline & LBM (kg) & $4.5 \pm 1.5$ & $6.5 \pm 1.7$ & $<0.001$ \\
\hline & PMM (kg) & $4.3 \pm 1.4$ & $6.2 \pm 1.7$ & $<0.001$ \\
\hline \multirow[t]{4}{*}{ Right arm } & Fat percentage (\%) & $31.0 \pm 4.7$ & $29.4 \pm 5.3$ & $0.343 *$ \\
\hline & Fat mass $(\mathrm{kg})$ & $0.5 \pm 0.2$ & $0.7 \pm 0.2$ & 0.005 \\
\hline & LBM (kg) & $1.1 \pm 0.4$ & $1.6 \pm 0.5$ & $<0.001$ \\
\hline & PMM (kg) & $1.1 \pm 0.4$ & $1.5 \pm 0.5$ & $<0.001$ \\
\hline \multirow[t]{4}{*}{ Left leg } & Fat percentage (\%) & $28.6 \pm 4.7$ & $26.4 \pm 5.8$ & $0.101 *$ \\
\hline & Fat mass (kg) & $1.8 \pm 0.8$ & $2.2 \pm 0.7$ & 0.017 \\
\hline & $\operatorname{LBM}(\mathrm{kg})$ & $4.3 \pm 1.5$ & $6.2 \pm 1.6$ & $<0.001$ \\
\hline & PMM (kg) & $4.1 \pm 1.4$ & $5.9 \pm 1.6$ & $<0.001$ \\
\hline \multirow[t]{4}{*}{ Left arm } & Fat percentage $(\%)$ & $31.8 \pm 5.2$ & $30.6 \pm 6.1$ & $0.412 *$ \\
\hline & Fat mass (kg) & $0.6 \pm 0.3$ & $0.7 \pm 0.2$ & 0.008 \\
\hline & $\operatorname{LBM}(\mathrm{kg})$ & $1.2 \pm 0.4$ & $1.7 \pm 0.5$ & $<0.001$ \\
\hline & PMM (kg) & $1.1 \pm 0.4$ & $1.6 \pm 0.5$ & $<0.001$ \\
\hline
\end{tabular}

Note. *No significant difference,

Abbreviations: LBM: Lean body mass, PMM: Predicted Muscle Mass.

A significant quantitative increase was found in body height, body weight and BMR value with age and physical growth. Although a numerical increase was seen in BMI value with age, it was not statistically significant. However, when the fat percentage rates considered as performance determinant were examined, it was seen that the rate of fat decreased with age in all parts of the body but this decrease was not statistically significant, with the increase in basal metabolism, the mass increased in the whole extremity in the regional body composition analysis but there was not any change proportionally (Table 3 ).

\section{Discussion}

While there was no significant difference in the SR values in kinematic parameters, as a result of the significant difference in SL and $50 \mathrm{~m} \mathrm{SR}, 50 \mathrm{~m}$ freestyle swimming degrees decreased with age. The unchanged SC per minute and the decrease in the degree indicate the increase in the strength.

Although a significant increase was observed in the physical characteristics and body composition with the increase in the biological age and years of experience; there was no significant difference in the body and segmental fat percentages. This can be explained by the fact that both fat weights and lean body weights of the athletes increased together, and as a result, the fat percentage did not differ significantly. Guo et al. found similar results in their study conducted with young people between the ages of 8-20 (Guo, Chumlea, Roche, \& Siervogel, 1998). As a result, with physical growth and development, years of experience leads to certain significant changes in body composition and athletic performance. It is thought that the follow-up of this process by coaches, which changes for each age group, will make a significant contribution to the swimming performance of athletes.

Calculated as the ratio of an individual's arm span relative to swimmers' height. In swimming it has been suggested that an Ape Index greater than 1.0, where the arm span is greater than the height, gives a com-petitive advantage in swimming (Geladas, Nassis, \& Pavlicevic, 2005; Lavoie \& Montpetit, 1986; Şenel \& Baykal, 2017; Stanula et al., 2012). In our group, the APE index values of the swimmers below 12 years of age were found to be $1.004 \pm 0.026$ and the values of the swimmers above 12 years of age were found to be $1.023 \pm 0.024$. Obtaining a value higher than 1 provides an advantage in swimming in terms of swimming mechanics. The 
swimmers, whose APE index value is over 1, can have better degrees compared to those with a value of under 1 although they have the same SR value (Dimitric, Cokorilo, \& Bogdanovski, 2016).

Improvement of the swimming performance with age is an expected result. With the increase in SL with physical growth, it becomes difficult to carry the increased body mass, but the effect of strength workouts in trainings is evident at this point. In this period, it is important to include different speed variation exercises in trainings.

SR enables the management of swimming fitness level. In terms of the athlete, it provides the control of training and competition data such as speed, race lap time and training lap time. In terms of the coach, it is important to create race and training strategies and compare them. Performance gains may include individual differences according to the structure of the training period (Ferreira et al., 2019; Hellard et al., 2008). It prevents injury when properly planned ("Application of improving swimming to the correction of joint and ligament students," 2013). There is no specific SR value as performance determinant (Şenel \& Baykal, 2017). Because the SR varies according to the swimmer's physical capacity, body structure, foot stroke rate, stroke frequency, distance covered on one stroke (stroke strength), gender, age and swimming distance (Hellard et al., 2008).

In the light of the data obtained, if the swimmer wants to improve SR, he should first increase his speed without changing (i.e., shortening) the stroke length. The greater the distance per unit time, the higher the velocity. From this point of view, the speed will increase when the swimmer increases the SR. However, the distance covered in return for the increased SR should also increase evenly. Low strength is an undesirable situation in the swimmer. In addition, since the stroke frequency in a second makes the swimmer cover a certain distance thanks to the existing SL without using any force, the increase in the frequency at the rate of the force is more valuable compared to the increase in the SR rate. This is the most valuable result of our study. All of these technical exercises should continue throughout the season and should be continued as a support in order to ensure that the performance does not fall behind between the seasons (Zacca et al., 2019). Resistance and strength exercises that can be applied in the water will have a positive effect on the development of these parameters (Gourgoulis, Valkoumas, Boli, Aggeloussis, \& Antoniou, 2019).

In the literature, there are very few studies conducted on the mechanical parameters affecting performance. The current studies have mainly focused on older age groups. The studies examining the swimming performances, performance components and body structures of the swimmers in the 10-16 age group according to age categories are limited in the literature and mostly biomechanical data are included (Martinez-Sobrino, Veiga, \& Navandar, 2017). Although the selected age group has not yet completed its technical development with its characteristics, it is a group in the physical developmental period. It is known that the training load intensities that children and young people are exposed to during their developmental periods affect their development. In recent years, in the formation of training and competition strategies of swimmers, individual tour turns durations, stroke counts and rates as well as their degrees are important in terms of their performances. In this period, information about the components that affect performance of the children engaged in swimming should be included in their education since this will be effective in order to manage their own performances in later years. Both coaches and swimmers should have the knowledge and equipment to increase their efficiency in trainings and this should be a prerequisite for swimming at better degrees. In all swimming teams that attach importance to age group development, in addition to their physiological development, it is also aimed to draw attention to performance components. It is thought that the data obtained will lead to individual development and development as a team and will guide coaches that train swimmers of this age group.

\section{Acknowledgements}

This study was presented as oral presentation at the 2nd World Congress of Sport Sciences Researches in 2019. The authors declare no conflict of interest.

\section{Referencess}

Application of improving swimming to the correction of joint and ligament students. (2013). Physical Education of Students, 5, 46-54. https://doi.org/10.6084/m9.figshare.771046

Aspenes, S., Kjendlie, P. L., Hoff, J., \& Helgerud, J. (2009). Combined strength and endurance training in competitive swimmers. Journal of Sports Science and Medicine, 8(3), 357-365.

Barbosa, A. C., Valadão, P. F., Wilke, C. F., Martins, F. de S., Silva, D. C. P., Volkers, S. A., ... Barroso, R. (2019). The road to 21 seconds: A case report of a 2016 Olympic swimming sprinter. International Journal of Sports Science and Coaching, 14(3), 393-405. https://doi.org/10.1177/1747954119828885

Barbosa, T. M., Fernandes, R. J., Keskinen, K. L., \& Vilas-Boas, J. P. (2008). The influence of stroke mechanics into energy cost of elite swimmers. European Journal of Applied Physiology, 103(2), 139-149. 
https://doi.org/10.1007/s00421-008-0676-z

Craig, A. B., \& Pendergast, D. R. (1979). Relationships of stroke rate, distance per stroke, and velocity in competitive swimming. Medicine and Science in Sports, 11(3), 278-183. https://doi.org/10.1249/00005768-197901130-00011

Dimitric, G., Cokorilo, N., \& Bogdanovski, M. (2016). Relations between Anthropometric Characteristics and Motor Abilities of 14-15U Female Swimmers on 50m Result for each Technique, 14, 37-40.

Ferreira, S., Carvalho, D., Monteiro, A., Abraldes, J., Vilas-Boas, J., Toubekis, A., \& Fernandes, R. (2019). Physiological and Biomechanical Evaluation of a Training Macrocycle in Children Swimmers. Sports, 7(3), 57. https://doi.org/10.3390/sports7030057

Geladas, N. D., Nassis, G. P., \& Pavlicevic, S. (2005). Somatic and physical traits affecting sprint swimming performance in young swimmers. International Journal of Sports Medicine, 26(2), 139-144. https://doi.org/10.1055/s-2004-817862

Gourgoulis, V., Valkoumas, I., Boli, A., Aggeloussis, N., \& Antoniou, P. (2019). Effect of an 11-Week In-Water Training Program with Increased Resistance on the Swimming Performance and the Basic Kinematic Characteristics of the Front Crawl Stroke. Journal of Strength and Conditioning Research, 33(1), 95-103. https://doi.org/10.1519/JSC.0000000000001879

Guo, S. S., Chumlea, W. C., Roche, A. F., \& Siervogel, R. M. (1998). Age- and maturity-related changes in body composition during adolescence into adulthood: The Fels longitudinal study. Applied Radiation and Isotopes, 49(5-6), 581-585. https://doi.org/10.1016/S0969-8043(97)00190-5

Hellard, P., Dekerle, J., Avalos, M., Caudal, N., Knopp, M., \& Hausswirth, C. (2008). Kinematic measures and stroke rate variability in elite female 200-m swimmers in the four swimming techniques: Athens 2004 Olympic semi-finalists and French National 2004 Championship semi-finalists. Journal of Sports Sciences, 26(1), 35-46. https://doi.org/10.1080/02640410701332515

Lavoie, J.-M., \& Montpetit, R. R. (1986). Applied Physiology of Swimming. Sports Medicine, 3(3), 165-189. https://doi.org/10.2165/00007256-198603030-00002

Martinez-Sobrino, J., Veiga, S., \& Navandar, A. (2017). Evaluation of Arm-To-Leg Coordination in Freestyle Swimming. European Journal of Human Movement, 38, 27-39.

Menting, S. G. P., Elferink-Gemser, M. T., Huijgen, B. C., \& Hettinga, F. J. (2019). Pacing in track based head-to-head competitions: a review on swimming. Journal of Sports Sciences, 37(20), 2287-2299. https://doi.org/10.1080/02640414.2019.1627989

Natation-FINA, F. I. De. (2015). FINA \& AQUATICS, A bit of history.

Şenel, Ö., \& Baykal, C. (2017). The relationship between stroke-rate, stroke-length and some anthropometric features in 11-12 years old swimmers $<\mathrm{p}>11-12$ yaş yüzücülerde kulaç oranı ve kulaç uzunluğunun bazı antropometrik özelliklerle ilişkisi. Journal of Human Sciences, 14(4), 4077. https://doi.org/10.14687/jhs.v14i4.5088

Stanula, A., Maszczyk, A., Roczniok, R., Pietraszewski, P., Ostrowski, A., Zajac, A., \& Strzała, M. (2012). The development and prediction of athletic performance in freestyle swimming. Journal of Human Kinetics, 32(1), 97-107. https://doi.org/10.2478/v10078-012-0027-3

Veiga, S., Rodriguez, L., González-Frutos, P., \& Navandar, A. (2019). Race Strategies of Open Water Swimmers in the 5-km, 10-km, and 25-km Races of the 2017 FINA World Swimming Championships. Frontiers in Psychology, 10(MAR). https://doi.org/10.3389/fpsyg.2019.00654

Weimar, W., Sumner, A., Romer, B., Fox, J., Rehm, J., Decoux, B., \& Patel, J. (2019). Kinetic Analysis of Swimming Flip-Turn Push-Off Techniques. Sports, 7(2), 32. https://doi.org/10.3390/sports7020032

Zacca, R., Toubekis, A., Freitas, L., Silva, A. F., Azevedo, R., Vilas-Boas, J. P., ... Fernandes, R. J. (2019). Effects of detraining in age-group swimmers' performance, energetics and kinematics. Journal of Sports Sciences, 37(13), 1490-1498. https://doi.org/10.1080/02640414.2019.1572434

\section{Copyrights}

Copyright for this article is retained by the author, with first publication rights granted to the journal.

This is an open-access article distributed under the terms and conditions of the Creative Commons Attribution license (http://creativecommons.org/licenses/by/4.0/). 